\title{
CHEMICAL COMPOSITION AND ANTIMICROBIAL ACTIVITY OF THE COMMERCIAL ORIGANUM ONITES L. OIL AGAINST NOSOCOMIAL CARBAPENEM RESISTANT EXTENDED SPECTRUM BETA LACTAMASE PRODUCER ESCHERICHIA COLI ISOLATES
}

\author{
Banu Kaskatepe, ${ }^{*}$ * Serap Suzuk Yildiz, ${ }^{2}$ Merve Eylul Kiymaci, ${ }^{1}$ \\ Ayse Nur Yazgan, ${ }^{3}$ Salih Cesur ${ }^{4}$ and Sinem Aslan Erdem ${ }^{3}$ \\ ${ }^{1}$ Department of Pharmaceutical Microbiology, Ankara University, Ankara, Turkey \\ ${ }^{2}$ National Antimicrobial Resistance Laboratory, Public Health Institution of Turkey, Ankara, Turkey \\ ${ }^{3}$ Department of Pharmacognosy, Ankara University, Ankara, Turkey \\ ${ }^{4}$ Department of Infection Diseases, Ankara Training Hospital, Ankara, Turkey
}

(Received: July 10, 2017; accepted: September 13, 2017)

\begin{abstract}
In recent years rapidly growing antibiotic resistance has increased interest toward natural products, especially essential oils because of their various effects. The aim of this study was to identify the chemical composition of the commercial Origanum onites essential oil (EO) and to investigate the antimicrobial activity by disc diffusion and dilution methods, against ten different ATCC strains, including eight bacteria, two yeasts and seventy-nine clinical nosocomial Escherichia coli isolates that produce extended spectrum beta lactamase (ESBL). The chemical composition of EO was analyzed by GC and GC-MS. The major compounds of the EO were determined as carvacrol $(51.4 \%)$ followed by linalool $(11.2 \%)$, p-cymene $(8.9 \%)$ and $\gamma$-terpinene $(6.7 \%)$. O. onites $\mathrm{EO}$ had antimicrobial activity against all standard strains and inhibited microbial growth of ESBL positive E. coli isolates. According to our results, $O$. onites EO may be an alternative to synthetic drug, used in combination with other antibiotics for treatment of infection caused by multidrug resistant bacteria after testing toxic effects and irritation at preferred doses on human.
\end{abstract}

Keywords: Antimicrobial activity - nosocomial ESBL (+) E. coli-GC/MS - Origanum onites essential oil

\section{INTRODUCTION}

The important elements in the formation of resistance to antibiotics in Enterobacteriaceae is ESBL production. ESBLs are the enzymes that are carried by the bacterial plasmids. They are very important due to cause resistance to a large number of extended spectrum beta-lactam antibiotics and spread very quickly. ESBL producing microorganisms cause serious infections especially in the intensive care unit [9]. Carbapenem group antibiotics are used for the treatment of these infections.

\footnotetext{
*Corresponding author; e-mail address: banu.kaskatepe@ankara.edu.tr
} 
Nosocomial infections that appeared with resistant bacteria in recent years are a worldwide problem. The vast majority of nosocomial infections due to resistant bacteria are increasingly developed by Gram negative bacteria. World Health Organization (WHO) published its antibiotic resistant "priority pathogens" catalogue in 2017. This catalogue is divided into three categories (critical, high and medium) according to urgency of need for new antibiotics and includes 12 families of bacteria that pose threat to human health. Carbapenem resistant ESBL producer Enterobacteriaceae familiy is classified into the critical priority group.

Due to drug resistant pathogens, new and alternative antimicrobial sources are sought for successful treatment of infectious diseases. Plants are important sources for drug discovery and development regarding especially their secondary metabolites. Essential oils (EO) are one of the secondary metabolites of plants that possess antibacterial, antifungal and antiviral activities and have been explored as potential sources for novel antimicrobial agents or supporting to treat infectious diseases and promoters for food preservation $[6,29]$. EOs and their rich biologically active components are widely used in different areas like folk medicine, cosmetic and food industry, etc.

Origanum, Satureja, Thymbra, Thymus and Coridothymus capitatus species are generally known as "kekik (thyme)" in Turkey due to their thyme-like odor. The genus Origanum is represented in Turkey by 32 taxa of which 21 is endemic [3]. Origanum onites (O. onites, Syn. O. smyrnaeum L.), known as "Turkish oregano" is on the top of the list of commercial Origanum species of Turkey and composes over $80 \%$ of all the oregano exports of Turkey [12] Origanum is regarded among the oilrich generas [5]. Regarding their traditional applications, they were experimentally tested and $O$. onites found to possess antimicrobial, antioxidant and antispasmodic activities [3,23] likewise other Origanum species [22].

The chemical composition of the EOs depends on climatic, seasonal, geographic, and soil conditions, the harvest period, and the distillation technique. The antibacterial activity of the EOs is dependent on the composition and concentration of the EO, the type and concentration of the target microorganism. In addition to this, EO of $O$. onites samples obtained from different origins have been found to contain different major compounds, regarded as chemotypes. The $\mathrm{EO}$ of the chemotypes is found to be rich in carvacrol (67-82\%) or linalool (80-92\%); besides, there is one more chemotype that contains carvacrol (36-66\%) and linalool (15-52\%) [12].

In the present study, it was aimed to identify the composition of the commercial $O$. onites EO and determine the antimicrobial activity of $O$. onites EO against ESBL positive nosocomial $E$. coli isolates with different methods. To our best knowledge, there are no available data on the antimicrobial activity of $O$. onites EO against to nosocomial ESBL positive strains. 


\section{MATERIALS AND METHODS}

\section{Essential oil sample}

The EO with serial number (8699851364106) was supplied from Tabia Company that produces commercial EOs. The EO was obtained from aerial parts of $O$. onites by hydrodistillation. Two of the EOs were analyzed by GC/MS. Their EO profiles were identical, so, the analyses were continued with one of the samples.

\section{Gas Chromatography-Mass Spectrometry analysis of essential oil}

Analysis of the EO was done simultaneously by gas chromatography (GC) and gas chromatography-mass spectrometry (GC/MS) systems. GC analysis was performed on an Agilent 6890N Network GC system (Agilent Technologies, USA) and GC/MS analysis was performed on Agilent 5973 Network Mass Selective Detector (Agilent Technologies, USA) integrated with the GC system. The analysis was performed using HP-Innowax column $(60.0 \mathrm{~m} \times 0.25 \mathrm{~mm} \times 0.25 \mathrm{~mm})$ (Agilent Technologies, USA) and Helium as carrier gas $(1.2 \mathrm{~mL} / \mathrm{min})$. The oven temperature was set to $60{ }^{\circ} \mathrm{C}$ for 10 min after injection, then increased to $220^{\circ} \mathrm{C}$ with $4{ }^{\circ} \mathrm{C} / \mathrm{min}$ heating ramp for $10 \mathrm{~min}$ and increased to $240{ }^{\circ} \mathrm{C}$ with $1{ }^{\circ} \mathrm{C} / \mathrm{min}$ heating ramp without hold. Both injector and detector (FID) temperatures were $250^{\circ} \mathrm{C}$; split ratio was adjusted to 20:1. Injection volume was $2.0 \mu \mathrm{L}$. MS conditions were as follows: ionization energy, $70 \mathrm{eV}$; ion source temperature, $280{ }^{\circ} \mathrm{C}$; interface temperature, $250{ }^{\circ} \mathrm{C}$; mass range, 34-450 atomic mass units.

Identification of the components was assigned by comparison of their relative retention indices and mass spectra with corresponding data [1] and by comparison of their mass spectras with Wiley and Nist library datas. The percentages of the components were calculated from the GC peak areas, using the normalization method.

\section{Bacterial strains and antimicrobial activity}

Eleven collection strains including Escherichia coli ATCC 25922, Escherichia coli ATCC 35218, Staphylococcus aureus ATCC 29213, Staphylococcus aureus ATCC 43300, Staphylococcus epidermidis ATCC 35984, Staphylococcus epidermidis ATCC 12228, Candida albicans ATCC 10231, Candida albicans ATCC 033, Pseudomonas aeruginosa ATCC 27853, Pseudomonas aeruginosa ATCC 9027, Bacillus subtilis ATCC 6633 obtained from American Type Culture Collection were used in this study. Additionally, extended spectrum beta lactamase (ESBL) producer, carbapenem resistant $79 \mathrm{E}$. coli isolates identified as causative agents of nosocomial infections in various hospitals in Turkey, were included in the study. Second strains isolated from same patients were excluded. The ESBL production of isolates was tested by the Double Disc Synergy Test according to CLSI standards [10]. Three different tests including 
disc diffusion, agar dilution and micro-dilution were performed for determination of antimicrobial susceptibility of the strains.

\section{Disc diffusion method}

Primarily antibacterial and antifungal activities of O.onites EO were determined by disc diffusion method to get an idea about antimicrobial effects of EO for further study. Each assay was performed in duplicate. After disc diffusion test, $O$. onites $\mathrm{EO}$ was found more effective against E. coli ATCC 25922 and E. coli ATCC 35218 compare to other standard strains therefore ESBL positive nosocomial E.coli isolates were selected for the other antibacterial activity tests.

\section{Agar dilution methods}

Agar dilution method was the first method used in this study for the determination of the minimum inhibitory concentration (MIC) of $O$. onites EO. Agar plates were prepared as containing different concentration of EO. For this, firstly different concentrations of EO were prepared, and then MHA melted and warmed to approximately at $45-50{ }^{\circ} \mathrm{C}$. The different concentrations of EO were poured into agar at a ratio of 1/10. It was allowed that the surface of the agar plates to dry before use. Bacterial suspensions were adjusted to Mc Farland 0.5 with turbidity with nephelometer and diluted at ratio $1 / 10$ and added the inoculum suspension to the multi-point inoculator wells. The suspension transferred to the surface of agar plates including a control plate without EO with apparatus of multi-point inoculator. The agar plates were incubated at $37^{\circ} \mathrm{C}$ for $16-20 \mathrm{~h}$. After incubation MIC was determined as the lowest concentration without visible growth. The test for each isolates was repeated three times.

\section{Micro-dilution method}

The MIC value of $O$. onites EO was determined by broth micro-dilution method according to The European Committee on Antimicrobial Susceptibility Testing (EUCAST) standards [13]. First, $100 \mu \mathrm{L}$ Mueller-Hinton Broth (MHB) was distributed into 96-well micro titer plates. Then EO at a $100 \mu \mathrm{L} / \mathrm{mL}$ final concentration was added and serially diluted by two-fold dilution. Bacterial suspension was prepared with phosphate buffered saline from fresh culture of bacteria and adjusted to turbidity equivalent to McFarland 0.5 with nephelometer. The turbidity was diluted at a ratio $1 / 100$ in MHB to obtain a final density of $5 \times 10^{5} \mathrm{cfu} / \mathrm{mL}$. Finally, $100 \mu \mathrm{L}$ of this bacterial suspension was added to each well. Agar plates were incubated at $37^{\circ} \mathrm{C}$ for 16-20 h. The lowest concentration that inhibits growth was determined as MIC value. The test for each isolates was repeated three times. 


\section{Statistical analysis}

The correlation between agar dilution and micro-dilution methods was evaluated using correlation test with SPSS for Windows packet program (Version 20).

\section{RESULTS}

Turkish oregano EO was analyzed by GC/MS to clarify the components in this study. Composition of the EO is given in (Table 1). O. onites EO was found most effective against E. coli ATCC 25922 and E. coli ATCC 35218 with $40 \mathrm{~mm}$. For this reason, ESBL positive nosocomial $E$. coli strains were included in the study for determination antimicrobial activity of $O$. onites EO. The results of antimicrobial activity test

Table 1

Composition of the essential oil (\%) of $O$. onites

\begin{tabular}{|c|c|c|c|}
\hline & $\mathrm{RRI}^{\mathrm{a}}$ & Compounds & Area \% \\
\hline 1 & 1015 & Methyl 2-methylbutyrate & $\operatorname{tr}^{\mathrm{b}}$ \\
\hline 2 & 1033 & $\alpha$-Pinene & 0.7 \\
\hline 3 & 1034 & $\alpha$-Thujene & 1.6 \\
\hline 4 & 1070 & Camphene & 0.4 \\
\hline 5 & 1107 & $\beta$-Pinen & 0.2 \\
\hline 6 & 1148 & $\delta$-3-Carene & 0.1 \\
\hline 7 & 1158 & $\beta$-Myrcene & 2.4 \\
\hline 8 & 1162 & $\alpha$-Phellandrene & 0.4 \\
\hline 9 & 1179 & $\alpha$-Terpinene & 1.6 \\
\hline 10 & 1197 & Limonene & 0.4 \\
\hline 11 & 1204 & 1,8-Cineole & $\operatorname{tr}$ \\
\hline 12 & 1207 & $\beta$-Phellandrene & 0.3 \\
\hline 13 & 1226 & (Z)- $\beta$-Ocimene & 0.2 \\
\hline 14 & 1242 & $\gamma$-Terpinene & 6.7 \\
\hline 15 & 1262 & p-Cymene & 8.9 \\
\hline 16 & 1274 & $\alpha$-Terpinolene & 0.2 \\
\hline 17 & 1402 & 1-Octen-3-ol & 0.3 \\
\hline 18 & 1425 & trans-Sabinene hydrate & 0.9 \\
\hline 19 & 1434 & cis-Linalool oxide & $\operatorname{tr}$ \\
\hline 20 & 1499 & Linalool & 11.2 \\
\hline 21 & 1508 & cis-Sabinene hydrate & 0.6 \\
\hline 22 & 1520 & Linalyl acetate & 0.5 \\
\hline 23 & 1577 & Terpinen-4-ol & 1.0 \\
\hline
\end{tabular}


Table 1 (cont.)

\begin{tabular}{|c|c|c|c|}
\hline & $\mathrm{RRI}^{\mathrm{a}}$ & Compounds & Area $\%$ \\
\hline 24 & 1580 & Carvacrol methyl ether & 0.2 \\
\hline 25 & 1596 & trans-Dihydrocarvone & $\operatorname{tr}$ \\
\hline 26 & 1610 & Caryophyllene & 1.5 \\
\hline 27 & 1635 & trans-Pinocarveol & $\operatorname{tr}$ \\
\hline 28 & 1673 & $\alpha$-Terpineol & 0.2 \\
\hline 29 & 1682 & Borneol & 1.2 \\
\hline 30 & 1729 & $\beta$-Bisabolene & 2.9 \\
\hline 31 & 1766 & $\delta$-Cadinene & 0.1 \\
\hline 32 & 1820 & para-Cymen-8-ol & $\operatorname{tr}$ \\
\hline 33 & 1854 & Carvacryl acetate & 0.2 \\
\hline 34 & 2000 & Caryophyllene oxide & 0.4 \\
\hline 35 & 2116 & Spathulenol & 0.2 \\
\hline 36 & 2147 & Thymol & 2.0 \\
\hline 37 & 2186 & Carvacrol & 51.4 \\
\hline \multicolumn{3}{|c|}{ Monoterpene hydrocarbons } & 23.9 \\
\hline \multicolumn{3}{|c|}{ Oxygenated monoterpenes } & 69.6 \\
\hline \multicolumn{3}{|c|}{ Sesquiterpene hydrocarbons } & 4.5 \\
\hline \multicolumn{3}{|c|}{ Oxygenated sesquiterpenes } & 0.6 \\
\hline \multicolumn{2}{|l|}{ Others } & \multicolumn{2}{|c|}{0.3} \\
\hline \multicolumn{2}{|c|}{ Total identified } & \multicolumn{2}{|c|}{98.9} \\
\hline
\end{tabular}

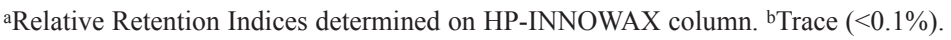

Table 2

Inhibition zone diameters of microorganisms for $O$. onites essential oil

\begin{tabular}{|l|c|}
\hline \multicolumn{1}{|c|}{ Strains } & Zone diameter $(\mathrm{mm})$ \\
\hline E.coli ATCC 25922 & 40 \\
\hline E.coli ATCC 35218 & 40 \\
\hline S.aureus ATCC 29213 & 30 \\
\hline S.aureus ATCC 43300 & 30 \\
\hline S.epidemidis ATCC 35984 & 24 \\
\hline P.aeruginosa ATCC 27853 & 30 \\
\hline P.aeruginosa ATCC 90027 & 30 \\
\hline B.subtilis ATCC 6633 & 30 \\
\hline C.albicans ATCC 10231 & 30 \\
\hline C.albicans ATCC 033 & 30 \\
\hline
\end{tabular}




\begin{tabular}{|c|c|c|c|c|c|c|c|c|c|c|c|c|}
\hline \multirow{21}{*}{ 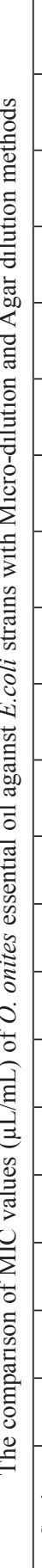 } & ন & $\stackrel{n}{\mathfrak{I}}$ & $\begin{array}{l}n \\
i \\
\end{array}$ & q & 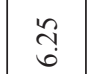 & તુ & 8 & $\stackrel{n}{\mathrm{i}}$ & $\stackrel{\sim}{\mathfrak{I}}$ & & & \\
\hline & 2 & 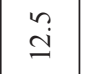 & $\approx$ & ले & તે & & in & & $\stackrel{\overbrace{}}{\tilde{\sigma}}$ & i & 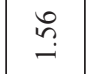 & $\frac{7}{m}$ \\
\hline & $\stackrel{\infty}{\simeq}$ & $\stackrel{\sim}{\underline{I}}$ & $\begin{array}{l}\text { તે } \\
\text { }\end{array}$ & $\infty$ & तે & & $\stackrel{\infty}{n}$ & 0 & $\stackrel{\tilde{c}}{\tilde{b}}$ & $\infty$ & $\frac{\sim}{m}$ & तิ \\
\hline & $=$ & $\stackrel{n}{\mathfrak{y}}$ & $\begin{array}{l}\text { î } \\
\text { ș }\end{array}$ & in & તి & & in & & ণิ & 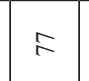 & $\ddot{\imath}$ & $\stackrel{2}{\imath}$ \\
\hline & $\underline{\bullet}$ & $\hat{\jmath}$ & $\stackrel{n}{\sim}$ & $\stackrel{m}{\circ}$ & సֶ. & & & $\theta$ & นิ & & $\tilde{a}$ & $\stackrel{\sim}{\underline{I}}$ \\
\hline & $\cong$ & $\approx$ & $\begin{array}{l}\text { तु } \\
\text { }\end{array}$ & $m$ & तె & & & 'ה & $\ddot{\imath}$ & 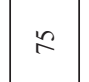 & 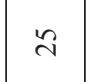 & $\stackrel{n}{\mathfrak{I}}$ \\
\hline & \pm & స్ & $\stackrel{n}{i}$ & $\dot{m}$ & ֶి & & & & તิ તิ & & $\hat{\imath}$ & ֶુ \\
\hline & 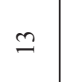 & तु & $\begin{array}{l}\text { तે } \\
\text { तु }\end{array}$ & $m$ & & & ? & î & तิ & & $\begin{array}{l}n \\
\text { in }\end{array}$ & $\stackrel{n}{\mathfrak{I}}$ \\
\hline & $\simeq$ & 4 & & $\approx$ & $\curvearrowleft$ & & & & $\stackrel{\sim}{\mathfrak{I}}$ & & $\stackrel{n}{i}$ & - \\
\hline & $=$ & $s$ & & $\bar{m}$ & & & & & $\stackrel{\sim}{\sim}$ & & & m \\
\hline & $\circ$ & $m$ & & i & & & in & & 1 & $R$ & $\begin{array}{l}\text { तु } \\
\text { (n) }\end{array}$ & 6 \\
\hline & $a$ & $\frac{1}{9}$ & & ते & $\ddot{\imath}$ & & gे & & $\stackrel{2}{6}$ & o & $\frac{\mathcal{T}}{m}$ & $\frac{\mathcal{I}}{m}$ \\
\hline & 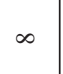 & ֶે & $\begin{array}{l}\text { ते } \\
\text { b }\end{array}$ & $\stackrel{\sim}{\sim}$ & ๙ & & 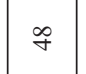 & î & $\ddot{\imath}$ & $\stackrel{\circ}{\circ}$ & $\ddot{2}$ & - \\
\hline & $r$ & $\stackrel{\sim}{m}$ & $\begin{array}{l}\text { ñ } \\
\text { S }\end{array}$ & $\hat{\lambda}$ & & & f & & 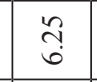 & 5 & \begin{tabular}{l}
$n$ \\
$\stackrel{n}{i}$ \\
\cline { 1 - 1 }
\end{tabular} & तु \\
\hline & 6 & $\stackrel{\sim}{\tilde{\sigma}}$ & î & $\lambda$ & $\stackrel{n}{\tilde{\sigma}}$ & 6 & f & $\ddot{n}$ & 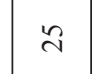 & 8 & $\stackrel{n}{i}$ & त̂ \\
\hline & $n$ & तె & 6 & is & & & $n$ & iิ & is & 6 & $\approx$ & $\sqrt{2}$ \\
\hline & ナ & s & $\approx$ & $\stackrel{d}{A}$ & & 1 & & & $\begin{array}{l}n \\
\stackrel{n}{i}\end{array}$ & t & - & वे \\
\hline & $m$ & $\ddot{\lambda}$ & $\ddot{\imath}$ & $\pi$ & $\ddot{\imath}$ & & 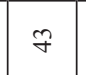 & & $\stackrel{n}{i}$ & 3 & $\stackrel{n}{i}$ & 6 \\
\hline & $\sim$ & तु & $\begin{array}{l}\text { त̂ } \\
\text { b }\end{array}$ & $\pi$ & $\begin{array}{l}n \\
\\
\end{array}$ & 6 & F & & तె & ک & $\stackrel{\sim}{m}$ & $\underset{\sim}{\sim}$ \\
\hline & $\ldots$ & ? & & ר & $\curvearrowleft$ & & $\bar{F}$ & $\ddot{\imath}$ & तु & $\bar{\sigma}$ & $\stackrel{n}{\simeq}$ & $n$ \\
\hline & 寻 & 号: & 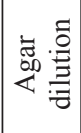 & 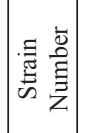 & : & 商 & 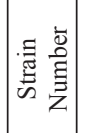 & 总. & 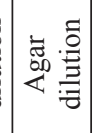 & 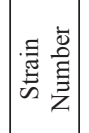 & 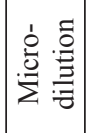 & 壱 \\
\hline
\end{tabular}

Acta Biologica Hungarica 68, 2017 
according to disc diffusion method for all standard strains are shown in (Table 2). In the second part of the study, micro-dilution and agar dilution methods were used for determining MIC values of oil due to importance of obtaining of inhibitory concentration in antimicrobial activity tests. MIC values determined with micro-dilution and agar dilution methods for $O$. onites EO against ESBL positive nosocomial $E$. coli isolates are given in (Table 3). According to the results of statistical test, positive correlation ( $\mathrm{p}=0.722)$ was determined between two methods. Our results obtained with two methods, were found to be compatible with each other. MIC values of $E$. coli ATCC 25922 and E. coli ATCC 35218 were determined and found $1.56 \mu \mathrm{L} / \mathrm{mL}$ and $6.25 \mu \mathrm{L} / \mathrm{mL}$ with micro-dilution method and $3.12 \mu \mathrm{L} / \mathrm{mL}$ and $6.25 \mu \mathrm{L} / \mathrm{mL}$ with agar dilution method respectively. Clinical ESBL positive E. coli strains were included in the study for determining antimicrobial activity of $O$. onites $\mathrm{EO}$ with two different methods. The ranges of MIC values are $1.56-25 \mu \mathrm{L} / \mathrm{mL}$ and $3.12-25 \mu \mathrm{L} / \mathrm{mL}$ for micro-dilution and agar dilution methods, respectively. There is a positive correlation between two methods. These two methods were performed for E. coli ATCC 25922 and E. coli ATCC 35218 strains. MIC values of E. coli ATCC 25922 and E. coli ATCC 35218 were found $1.56 \mu \mathrm{L} / \mathrm{mL}$ and $6.25 \mu \mathrm{L} / \mathrm{mL}$ with micro-dilution method and $3.12 \mu \mathrm{L} / \mathrm{mL}$ and $6.25 \mu \mathrm{L} / \mathrm{mL}$ with agar dilution method respectively. These results indicate that this $\mathrm{EO}$ is effective against $\mathrm{ESBL}$ positive $E$. coli isolates as ATCC strains.

\section{DISCUSSION}

Rapidly growing antibiotic resistance in recent years is an important problem for treatment of infection. Antimicrobial resistance observed increasingly in E. coli, may be explained by the spread of multidrug resistant plasmids that also contain genes for the production of ESBL. It is known that ESBL producing microorganisms cause serious infections, especially in the intensive care unit. This situation has increased interest toward natural products. Aerial parts of Origanum, Satureja, Thymbra, Thymus and Coridothymus capitatus species are generally known as "kekik (thyme)" in Turkey, and are used for herbal tea, condiments to soups, salads and meat meals, and essential oils as well as aromatic water [19]. Oregano water is taken orally for gastrointestinal disorders, to reduce blood cholesterol and glucose levels. Oregano EO is used as a painkiller in rheumatism by rubbing externally on the painful limbs [4]. In addition, oregano EO has antibacterial, antispasmodic, antiseptic, analgesic properties and also have digestive, reducing the blood glucose level, sedative, diuretic, menstrual regulator, cough suppressants and analgesics effects. O. onites exhibited complete inhibition of the following food-borne fungi Aspergillus flavus, Aspergillus niger and some other Penicillium species [2]. The major compounds of the oil were determined as carvacrol (51.4\%) followed by linalool $(11.2 \%), p$-cymene (8.9\%) and $\gamma$-terpinene (6.7\%). Carvacrol (5-isopropyl-2-methylphenol) is one of the main components of $O$. onites $\mathrm{EO}$ and produced in the plant as a result of chemical defense mechanism against microorganisms [31]. Thus the EO can be encountered as 
carvacrol-rich EO which is used for their high potency as antimicrobial and antifungal properties [18]. Studies conducted on various Origanum species revealed that the major component of these oils are predominantly carvacrol [7, 20, 25, 26, 30], besides thymol or linalool also can be found as major components [24, 25]. Kaçar et al. [16] have searched EO composition obtained from the leaves of $O$. onites in different agronomical traits and they found that oils contain carvacrol as major compound varying between $68.68 \%$ and $89.86 \%$. In another study, carvacrol (57.4\%) was found as major compound followed by thymol $(11.6 \%)$ from the EO obtained from aerial parts of $O$. onites EO [12]. In another study Baydar et al. [6] reported that EO obtained from $O$. onites aerial parts contains carvacrol (84.6\%) as major component. The results related with major components of $O$. onites EO that were obtained from literature survey are compatible with our present results. The antimicrobial nature of the EOs is apparently related to their high phenolic contents, particularly carvacrol and thymol, and this finding is in agreement with previous reports $[8,11]$. Natural terpenoid thymol and its phenol isomer carvacrol are known as representing the main compounds of oregano EO oil which are responsible for the antimicrobial activity [14]. Askun et al. [3] described that $O$. onites (the amount of carvacrol was 243.2 $\mu \mathrm{g} / \mathrm{mL}$ in the methanol extract of the plant) showed the best antimicrobial activity against $S$. typhimurium and E. aerogenes (MIC $640 \mu \mathrm{g} / \mathrm{mL}$ ) which also inhibited significantly S. epidermidis (MIC $640 \mu \mathrm{g} / \mathrm{mL}$ ) and M. tuberculosis (MIC $784 \mu \mathrm{g} / \mathrm{mL}$ ) but not $S$. aureus. Sarac and Ugur [23] determined similar antimicrobial activity for $O$. onites EO samples (collected from five different locations of Mugla) against Gram-positive and Gram-negative bacteria, and found that samples from Urla Pool location were more effective against B. subtilis, E. coli, S. maltophilia MU 99, and C. luteola than the others, with these zone of inhibition diameters respectively: 37 $\mathrm{mm}, 28 \mathrm{~mm}, 33 \mathrm{~mm}, 31 \mathrm{~mm}$, and 28-30 mm for C. albicans. Baydar et al. [6] determined that at 1/50 concentration of $O$. onites EO was effective against Aeromonas hydrophila, B. amyloliquefaciens, B. brevis, B. cereus, B. subtilis, Corynebacterium xerosis, E. faecalis, E. coli, K. pneumoniae, Listeria monocytogenes, Micrococcus luteus, M. smegmatis, $P$. vulgaris, $S$. aureus and $Y$. enterocolitica, by disc diffusion method, and also 1/100 concentration of EO inhibited the bacteria except $A$. hydrophila, B. cereus and E. coli. Mith et al. [21] demonstrated antimicrobial activity of oregano EOs against food spoilage bacteria. Also oregano EO is used for controlling plant diseases, particularly on fruit [15, 28]. Skandamis et al. [27] underlined that oregano EO $(0.8 \% \mathrm{v} / \mathrm{w})$ eliminated $S$. typhimurium from meat in conjuction with vacuum packaging.

According to our literature survey, there are no studies about antimicrobial activity of $O$. onites with a great number of nosocomial ESBL positive strains. The first important point of this study is the number and the speciality of the isolates used in the experiments. The second point is the comparison of the antimicrobial susceptibility test methods. Two methods were used for screening the antibacterial activity which are also recommended by EUCAST and CLSI, used in this study. Therefore the data were compared. The $O$. onites $\mathrm{EO}$ was found effective against nosocomial 
ESBL $E$. coli isolates with two methods. O. onites may be used in combination with other antibiotics for treatment of infection caused by multidrug resistant bacteria after further study, including toxic effects and irritation at preferred doses on human.

\section{REFERENCES}

1. Adams, R. P. (2001) Identification of Essential Oil Components by Gas Chromatography/Quadrupole Mass Spectroscopy. Allured Publishing Co., Illinois, USA.

2. Akgül, A., Kıvanç, M. (1998) Inhibitory effects of selected Turkish spices and oregano components on some food borne fungi, Intern. J. Food. Microbiol. 6, 263-268.

3. Askun, T., Tumen, G., Satil, F., Ates, M. (2009) Characterization of the phenolic composition and antimicrobial activities of Turkish medicinal plants. Pharm. Biol. 47, 563-571.

4. Baser, K. H. C. (2004) Domestic uses of Oregano in Turkey. In: Kitzios, S. E. (ed.) Oregano: The genera Origanum and Lippia. Taylor \& Francis, London, pp. 111

5. Baser, K. H. C. (2008) Biological and pharmacological activities of carvacrol and carvacrol bearing essential oils. Curr. Pharm. Design. 14, 106-3019.

6. Baydar, H., Sagdiç, O., Ozkan, G., Karadoğan, T. (2004) Antibacterial activity and composition of essential oils from Origanum, Thymbra and Satureja species with commercial importance in Turkey. Food Control. 15, 169-172.

7. Beklem Bostancioğlu, R., Kürkçüoğlu, M., Başer, K. H., Koparal, A. T. (2012) Assessment of antiangiogenic and anti-tumoral potentials of Origanum onites L. essential oil. Food Chem. Toxicol. 50, 2002-2008.

8. Boyraz, N., Ozcan, M. (2006) Inhibition of phytopathogenic fungi by essential oil, hydrosol, ground material and extract of summer savory (Satureja hortensis L.) growing wild in Turkey. Int. J. Food Microbiol. 107, 238-42

9. Cantón, R., Novais, A., Valverde, A., Machado, E., Peixe, L. Baquero, F. (2008) Prevalence and spread of extended-spectrum beta-lactamase-producing Enterobacteriaceae in Europe. Clin. Microbiol. Infect. 14, 144-153.

10. CLSI (2013) Performance Standards for Antimicrobial Susceptibility Testing, Twenty-Third Informational Supplement, Wayne PA, M100-S23, Vol. 33, No.1, January.

11. Cosentino, S., Tuberoso, C. I., Pisano, B., Satta, M., Mascia, V., Arzedi, E., Palmas, F. (1999) Palmas, In-vitro antimicrobial activity and chemical composition of Sardinian Thymus essential oils. Lett. Appl. Microbiol. 29, 130-135.

12. Demirci, F., Paper, D. H., Franz, G., Başer, K. H. C. (2004) Investigation of the Origanum onites L. essential oil using the chorioallantoic membrane assay. J. Agr. Food Chem. 52, 251-254.

13. EUCAST (2016) Breakpoint tables for interpretation of MICs and zone diameters, Version 6.0. European Committee on Antimicrobial Susceptibility Testing (EUCAST); [cited 2016-01-01] Avaiablefrom: http://www.eucast.org.

14. Fachini-Queiroz, F. C., Kummer, R., Estevão-Silva, C. F., Barros Carvalho, M. D., Cunha, M. J. Grespan, R., Bersani-Amado, C. A., Cuman, R. K. N. (2012) Effects of Thymol and Carvacrol, Constituents of Thymus vulgaris L. Essential Oil, on the Inflammatory Response. J Evid Based Complementary Altern Med. vol. 2012, Article ID 657026, 10 pages.

15. Holley, R. A., Patel, D. (2005) Improvement of shelflife and safety of perishable foods by plant essential oils and smoke antimicrobials. Food Microbiol. 22, 273-292.

16. Kacar, O., Göksu, E., Azkan, N. (2006) The effect of different plant densites on some agronomic and quality characteristics of Oregano (Origanum onites L.) The Journal of Agricultural Faculty of Uludag University 2, 51-60.

17. Kan, Y., Uçan, U. S., Kartal, M., Altun, M. L., Aslan, S., Sayar, E., Ceyhan, T. (2006) GC-MS analysis and antibacterial activity of cultivated Satureja cuneifolia Ten essential oil. Turkish Journal of Chemistry 30, 253-259. 
18. Kintzios, S. E. (2002) Profile of thyme multifaceted prince of the herbs. In: Kitzios, S. E. (ed.) Oregano: The genera Origanum and Lippia. Taylor \& Francis, London, 3-8.

19. Kirimer, N., Başer, K. H. C., Tümen, G. (1995) Carvacrol-rich plants in Turkey. Chem Nat Compd. $31,37-41$.

20. Kordali, S., Cakir, A., Ozer, H., Cakmakci, R., Kesdek, M., Mete, E. (2008) Antifungal, phytotoxic and insecticidal properties of essential oil isolated from Turkish Origanum acutidens and its three components, carvacrol, thymol and p-cymene. Bioresource Technol. 99, 8788-8795.

21. Mith, H., Dure, R., Delcenserie, V., Zhiri, A., Daube, G., Clinquart, A. (2014) Antimicrobial activities of commercial essential oils and their components against food-borne pathogens and food spoilage bacteria. Food Sci Nutr. 2, 403-416.

22. Şahin, N. F., Güllüce, M., Dafererad, D., Sökmen, A., Sökmen, M., Polissioud, M., Agar, G., Özer, H. (2004) Biological activities of the essential oils and methanol extract of Origanum vulgare ssp. vulgare in the Eastern Anatolia region of Turkey. Food Control 15, 549-557.

23. Sarac, N., Ugur, A. (2008) Antimicrobial activities of the essential oils of Origanum onites L. Origanum vulgare L. subspecies hirtum (link) letswaart, Satureja thymbra L., and Thymus cilicicus Boiss. \& Bal. growing wild in Turkey. J Med Food. 11, 568-573.

24. Sarikurkcu, C., Zengin, G., Oskay, M., Uysal, S., Ceylan, R., Aktumsek, R. (2015) Composition, antioxidant, antimicrobial and enzyme inhibition activities of two Origanum vulgare subspecies (subsp. vulgare and subsp. hirtum) essential oils. Ind. Crops Prod. 70, 178-184.

25. Schulz, H., Özkan, G., Baranska, M., Krüger, H., Özcan, M. (2005) Characterization of essential oil plants from Turkey by IR and Raman spectroscopy. Vibrational Spectroscopy 39, 249-256.

26. Sertkaya, E., Kaya, K. (2010) Acaricidal activities of the essential oils from several medicinal plants against the carmine spider mite (Tetranychus cinnabarinus Boisd.) (Acarina: Tetranychidae). Ind Crops Prod. 31, 107-112.

27. Skandamis, P., Tsigarida, E., Nychas, G. J. E. (2002) The effect of oregano essential oil on survival/ death of Salmonella typhimurium in meat stored at $50{ }^{\circ} \mathrm{C}$ under aerobic, VP/MAP conditions. Food Microbiol. 19, 97-103.

28. Solgi, M., Kafi, M., Taghavi, T., Naderi, R. (2009) Essential oils and silver nanoparticles (SNP) as novel agents to extend vase-life of gerbera (Gerbera jamesonii cv. 'Dune') flowers. Postharvest Biol. Technol. 53, 155-158.

29. Solórzano-Santos, F., Miranda-Novales, M. G. (2012) Essential oils from aromatic herbs as antimicrobial agents. Curr. Opin Biotechnol. 23, 136-141.

30. Tozlu, E., Cakir, A., Kordali, S., Tozlu, G., Ozer, H., Akcin, T. A. (2011) Chemical compositions and insecticidal effects of essential oils isolated from Achillea gypsicola, Satureja hortensis, Origanum acutidens and Hypericum scabrum against broadbean weevil (Bruchus dentipes). Sci. Horticult. 130, 9-17.

31. Vázquez, B. I., Fente, C., Franco, C. M., Vázquez, M. J., Cepeda, A. (2001) Inhibitory effects of eugenol and thymol on Penicillium citrinum strains in culture media and cheese. Int. J. Food Microbiol. 67, 157-163. 